\title{
Modeling the sensitivity of hydrogeological parameters associated with leaching of uranium transport in an unsaturated porous medium
}

\author{
Berlin Mohanadhas $^{1^{\dagger}}$, Suresh Kumar Govindarajan ${ }^{2}$ \\ ${ }^{1}$ Department of Civil Engineering, National Institute of Technology, Arunachal Pradesh, Yupia, Papumpare, Arunachal Pradesh-791112, India \\ ${ }^{2}$ Department of Ocean Engineering, Indian Institute of Technology, Madras, Chennai-36, India
}

\begin{abstract}
The uranium ore residues from the legacies of past uranium mining and milling activities that resulted from the less stringent environmental standards along with the uranium residues from the existing nuclear power plants continue to be a cause of concern as the final uranium residues are not made safe from radiological and general safety point of view. The deposition of uranium in ponds increases the risk of groundwater getting contaminated as these residues essentially leach through the upper unsaturated geological formation. In this context, a numerical model has been developed in order to forecast the ${ }^{238} \mathrm{U}$ and its progenies concentration in an unsaturated soil. The developed numerical model is implemented in a hypothetical uranium tailing pond consisting of sandy soil and silty soil types. The numerical results show that the ${ }^{238} \mathrm{U}$ and its progenies are migrating up to the depth of $90 \mathrm{~m}$ and $800 \mathrm{~m}$ after $10 \mathrm{y}$ in silty and sandy soil, respectively. Essentially, silt may reduce the risk of contamination in the groundwater for longer time span and at the deeper depths. In general, a coupled effect of sorption and hydro-geological parameters (soil type, moisture context and hydraulic conductivity) decides the resultant uranium transport in subsurface environment.
\end{abstract}

Keywords: Numerical modeling, Sandy soil, Silty soil, Sorption, Uranium transport

\section{Introduction}

Uranium is a natural radioactive element which is available in three isotope forms of $\mathrm{U}^{238}, \mathrm{U}^{235}$ and $\mathrm{U}^{234}$ in the environment. After World War II, uranium was mined extensively for production of nuclear weapons and later for nuclear power plants to produce energy [1]. In India, $2.7 \%$ of the total electrical energy is produced from nuclear power plants [2]. Uranium element is extracted from uranium ore and the uranium ore residues are deposited in ponds. These ponds are referred as uranium tailing ponds, which contains the radioactive decay products of uranium and heavy metals [3, 4]. The major radiation risk for living organism from uranium tailings are exposure to gamma radiation, windblown radioactive dust dispersion and radon gas and its progenies [2]. The major environmental impacts of uranium tailings are failure of tailing dams, exposure to radiation,

This is an Open Access article distributed under the terms of the Creative Commons Attribution Non-Commercial License (http://creativecommons.org/licenses/by-nc/3.0/) which permits unrestricted non-commercial use, distribution, and reproduction in any medium, provided the original work is properly cited.

Copyright (C) 2018 Korean Society of Environmental Engineers surface and groundwater contamination due to leakage of radioactive and other toxic elements [3-5]. There are many studies executed earlier to treat various contaminants from water at various levels. Mercury sorption experiment has been performed by silica/carbon nanotubes and silica/activated carbon [6]. Various types of water treatment and recycling techniques have been discussed in terms of their basic principles, applications, costs, maintenance and suitability [7]. Saleh et al. [8] carried out a study on preparation and investigation of a multifunctional material that can be used in wastewater treatment for removal of arsenic. Further, Saleh [9] used Nanocomposite of carbon nanotubes/silica nanoparticles for adsorption of $\mathrm{Pb}(\mathrm{II})$. The activated carbon developed from waste rubber tires is identified as an efficient material for removal of Chromium from wastewater [10]. The experimental results demonstrate that the combining of silica and nanotubes is a promising alternative material, which can be used to remove the mercury from wastewaters [11]. Later,

Received August 29, 2017 Accepted May 3, 2018

${ }^{\dagger}$ Corresponding author

Email: berlin1982@gmail.com

Tel: +91-887-0890922 Fax: +91-360-2284972 
Zare et al. [12] conducted kinetic and thermodynamic studies for the efficient removal of radioactive uranium from solvent phase using nanoparticles, which exhibited excellent thermal stability and large surface area. Tawfik et al. [13] used polyethyleneimine modified activated carbon/Fe as an effective magnetic adsorbent to remove uranium ions from aqueous solution as a function of batch adsorption parameters; and it was concluded that the PAF magnetic sorbent could be considered as a promising and effective adsorbent for the purification of wastewaters from uranium ions. However, understanding the processes involved on the migration of radionuclide from uranium tailing pond to sub-surface is a necessary prerequisite for forecasting the long-term performance and prediction of groundwater quality.

Modeling the fate and transport of radioactive wastes has been known to be a valuable approach in accessing the radiological impact assessment of uranium tailing ponds in sub-soil system. The long-term impacts on release of uranium from tailing pond have been studied by many researchers using modeling approach [14-18]. Groundwater contamination due to leaching of uranium and its progenies from tailing ponds is a major concern. This may lead to unfit the groundwater for human consumption. The naturally occurring U, Th, Ra and Rn nuclides transport in groundwater are mostly controlled by physicochemical processes of weathering, decay and sorption at the water-rock interface [19, 20]. Rotter et al. [21] developed a biogeochemical reactive transport model for uranium immobilization in both single and dual-porosity porous media to study the bioremediation efficiency on uranium. Recently, a decay-chain transport of uranium in a heterogeneous anisotropic saturated porous medium is performed [22]. This study identified the necessity of monitoring the short-lived progeny radionuclides apart from their long-lived parents in the groundwater in the vicinity of uranium tailing ponds.

It is observed that many modeling studies are performed on transport of uranium in the saturated porous medium. The modeling studies to investigate the transport of radionuclide in unsaturated condition are very limited. Qian et al. [23] simulated the vertical transport of $\mathrm{Sr}^{90}$ in the unsaturated Chinese loess under artificial rain conditions. Merk [24] studied the radionuclide transport from the concrete rubble when the radionuclide dissolves in the infiltrated water using HYDRUS-1D. Sanchez and Thorne [25] presented a mathematical model to study the behavior of $\mathrm{U}^{238}$ series radionuclide entering soils in solution and their uptake by plants along with the decay chain of uranium in soil-plant system under different hydrological regimes. Nair et al. [26] developed a multi-compartmental source term model to assess the radionuclide leaching in a saturated or unsaturated porous medium such as a uranium tailing ponds.

Vadose zone thickness can extend several meters and the soil hydraulic parameters are nonlinear [27-31]. Few studies indicated the vadose zone thickness can extend up to $50 \mathrm{~m}$ [32]. The flow and transport of radionuclide is caused by unsaturated matrix permeability, porosity and sorption coefficient [33]. Further, experimental and modeling study confirms that the radionuclide migration in unsaturated zone is highly depend- ent on unsaturated van Genuchten parameter [34]. The modeling as well as experimental studies in field scale also discussed earlier on the migration of radionuclide in large vadose zone thickness [35-37]. Moreover, the transport behavior of uranium from the tailing pond has extremely affected under various soil types such as sand, silt, clay, sediments and sandstone [19, $20,23,24]$.

The mill tailings are expected to include all the radionuclide in the ${ }^{238} \mathrm{U}$ decay series after the uranium extraction from ore [22]. The ${ }^{238} \mathrm{U}$ decay chain contains four long-lived radionuclide $\left({ }^{238} \mathrm{U},{ }^{234} \mathrm{U},{ }^{230} \mathrm{Th},{ }^{226} \mathrm{Ra}\right)$; five short-lived nuclides $\left({ }^{234} \mathrm{Th},{ }^{222} \mathrm{Rn}\right.$, ${ }^{210} \mathrm{~Pb},{ }^{210} \mathrm{Bi}$, $\left.{ }^{210} \mathrm{Po}\right)$; and five very short-lived nuclides $\left({ }^{234 \mathrm{~m}} \mathrm{~Pa},{ }^{218} \mathrm{Po}\right.$, ${ }^{214} \mathrm{~Pb},{ }^{214} \mathrm{Bi},{ }^{214} \mathrm{Po}$ ). On the other hand, ${ }^{222} \mathrm{Rn}$ can escape from the ore and other short-lived progenies may decay to innocuous levels during the ore extraction processes. Thus, primarily uranium tailing ponds consists of long-lived radionuclide of ${ }^{238} \mathrm{U}$, ${ }^{234} \mathrm{U},{ }^{230} \mathrm{Th},{ }^{226} \mathrm{Ra}$. Subsequently, ingrowths of progenies will happen in the tailing ponds as well as in the percolated water.

Many modeling studies have been investigated on the migration of various radionuclides in the unsaturated porous medium. However, all long-lived, short-lived and very short-lived ${ }^{238} \mathrm{U}$ nuclide transport in unsaturated porous medium has not been analyzed extensively. Since, the uranium tailing ponds are located in the soil surface a suitable numerical model has to be developed for vertical transport of multi-species radionuclide incorporating the nonlinear soil hydraulic parameters under unsaturated condition. Hence, the motivation of the present work is to develop a one-dimensional decay chain transport model to predict the concentration of radionuclide from uranium tailing pond due to vertical leaching under unsaturated condition. Further, the developed model is extended to evaluate the transport of radionuclide in different soils which are generally available beneath the uranium tailing pond.

\section{Physical System and Governing Equations}

Uranium tailings ponds are generally located in unsaturated zones [26]. The vertical transport by soil water, of radionuclide from uranium tailings ponds, is of major concern in assessing the vulnerability of groundwater contamination. Fig. 1 illustrates the conceptual understanding of uranium transport in an unsaturated zone.

The equation of mass conservation can be coupled with the Darcy's law to produce the Richard's equation which governs the water flow in an unsaturated porous medium [38-40] that is used for this study is given in Eq. (1):

$$
C(h) \frac{\partial h}{\partial t}=\frac{\partial}{\partial z} K\left(\frac{\partial h}{\partial z}\right)-\frac{\partial K}{\partial z}
$$

Where: $C(h)=\frac{\partial \theta w}{\partial h}$ is specific moisture capacity $(1 / \mathrm{cm})$; $\theta_{w}$ is the volumetric water content $\left(\mathrm{cm}^{3} / \mathrm{cm}^{3}\right) ; h$ is the pressure head $(\mathrm{cm}) ; K$ is the unsaturated hydraulic conductivity $(\mathrm{cm} / \mathrm{s})$; $t$ is the time (s); $z$ is the vertical coordinate $(\mathrm{cm})$ positive downward. 


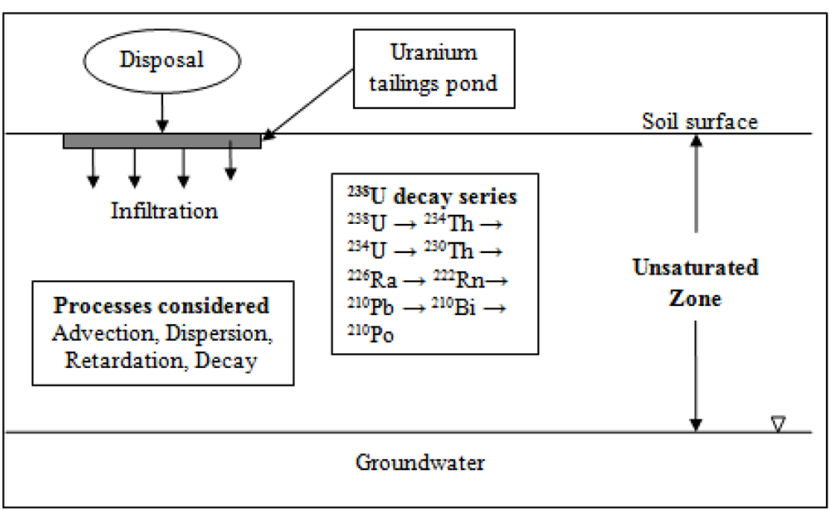

Fig. 1. Pictorial representation of uranium transport in unsaturated porous media.

In unsaturated porous medium, the part of pore space volume is filled by air. Hence, the moisture content $\theta_{w}$ is generally smaller than the porosity. The water pathway modeling in unsaturated porous system is considerably complicated as compared with saturated porous system. The water content $\left(\theta_{w}\right)$, pressure head (h) and hydraulic conductivity $(\mathrm{K})$ are highly correlated in the unsaturated case. The hydraulic conductivity in unsaturated porous medium is not only depends on the matrix material but also on the local pressure head [24]. Widely acknowledged empirical relationships were arrived by van Genuchten [41] and described in Eq. (2) and (3).

$$
\begin{gathered}
K(h)=K_{s}\left[\frac{\theta_{w}-\theta_{r}}{\theta_{s}-\theta_{r}}\right]^{1 / 2}\left[1-\left(1-\left[\frac{\theta_{w}-\theta_{r}}{\theta_{s}-\theta_{r}}\right]^{1 / \eta}\right)^{\eta}\right]^{2} \\
\theta_{w}=\theta_{r}+\left(\theta_{s}-\theta_{r}\right)\left[1+(\alpha|h|)^{\beta}\right]^{-\eta}
\end{gathered}
$$

where $\eta$ is an empirical constant affecting the shape of the retention curve, $\theta_{s}$ is the saturated water content, $\theta_{r}$ is the and residual water content, $\alpha$ and $\beta$ are both empirical constants.

The decay chain transport model for the parent radionuclide for a one-dimensional and homogeneous unsaturated porous medium can be represented as [22] expressed in Eq. (4):

$$
R_{1} \frac{\partial N_{1}}{\partial t}=\frac{\partial}{\partial z}\left(D \frac{\partial N_{1}}{\partial z}\right)-v \frac{\partial N_{1}}{\partial z}-R_{1} \lambda_{1} N_{1}
$$

where $N_{1}$ is the concentration of the parent radionuclide in the aqueous phase (atoms $\mathrm{L}^{-3}$ or mol); $D$ is the hydrodynamic dispersion coefficient $\left(\mathrm{L}^{2} \mathrm{~T}^{-1}\right)\left(D=\alpha_{L} \times v\right) ; \alpha_{L}$ is the longitudinal dispersivity (L) can be produced by different pore sizes along the flow paths and/or by tortuosity; $v$ is the pore water velocity $(\mathrm{L} / \mathrm{T})$ can be obtained by dividing the Darcy velocity by the effective porosity (which is expressed as $v=q / \theta_{w}$ ); $q$ is obtained from Darcy's law $q=-K\left[\frac{\partial(h-z)}{\partial z}\right] ; \lambda_{1}$ is the radioactive decay constant $\left(\mathrm{T}^{-1}\right)$.

Similarly, the decay chain transport equation for the $i^{\text {th }}$ member of the decay chain can be written [22] as given in Eq. (5):

$$
R_{i} \frac{\partial N_{i}}{\partial t}=\frac{\partial}{\partial z}\left(D \frac{\partial N_{i}}{\partial z}\right)-v \frac{\partial N_{i}}{\partial z}-R_{i} \lambda_{i} N_{i}+R_{i-1} \lambda_{i-1} N_{i-1}
$$

where $i>1$ to $M$; $M$ is the number of total nuclides involved in the decay chain. The ingrowth of the progenies from the previous parent radionuclide is included in the last term of Eq. (5). The sorption of radionuclides is described by linear and reversible. Hence, the retardation factor $\left(R_{i}\right)$ of the radionuclide ' $i$ ', which can be expressed in Eq. (6):

$$
R_{i}=1+\frac{k_{d i} \rho_{b}}{\theta_{w}}
$$

where $k_{d i}$ is the distribution coefficient of radionuclide ' $i$ ' $\left(\mathrm{L}^{3} \mathrm{M}^{-1}\right)$; $\rho_{b}$ is the bulk density of the porous material $\left(\mathrm{M} \mathrm{L}^{-3}\right)$. Fig. 2 illustrates the schematic representation of solving water flow and transport of radionuclides in an unsaturated porous medium.

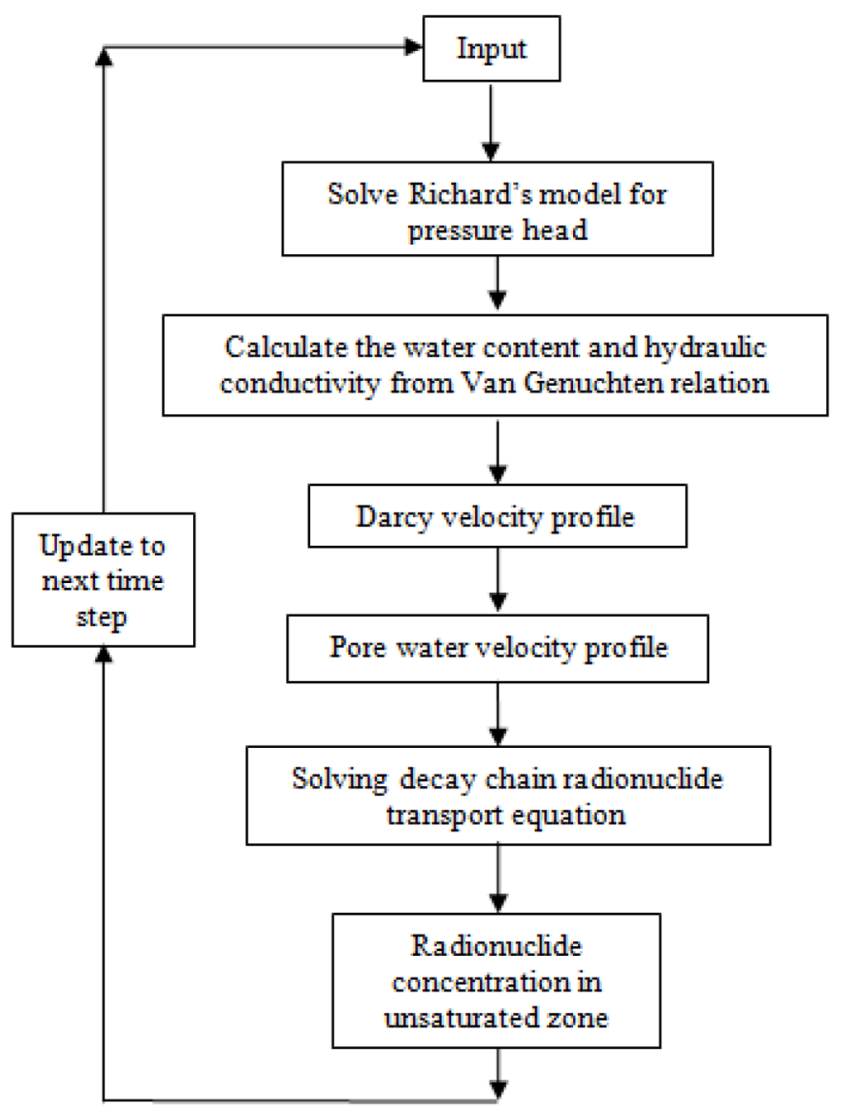

Fig. 2. Schematic representation of solving water flow and transport of radionuclides in an unsaturated porous medium.

\subsection{Initial and Boundary Conditions}

Initially the unsaturated soil is assumed as dry condition. An average infiltration rate of $10,3,0.75 \mathrm{~m} / \mathrm{y}$ was taken as top boundary for sand and silt soil with zero flux is used as the bottom boundary condition for water flow model. At the beginning of the numerical experiment, the unsaturated soil is assumed 


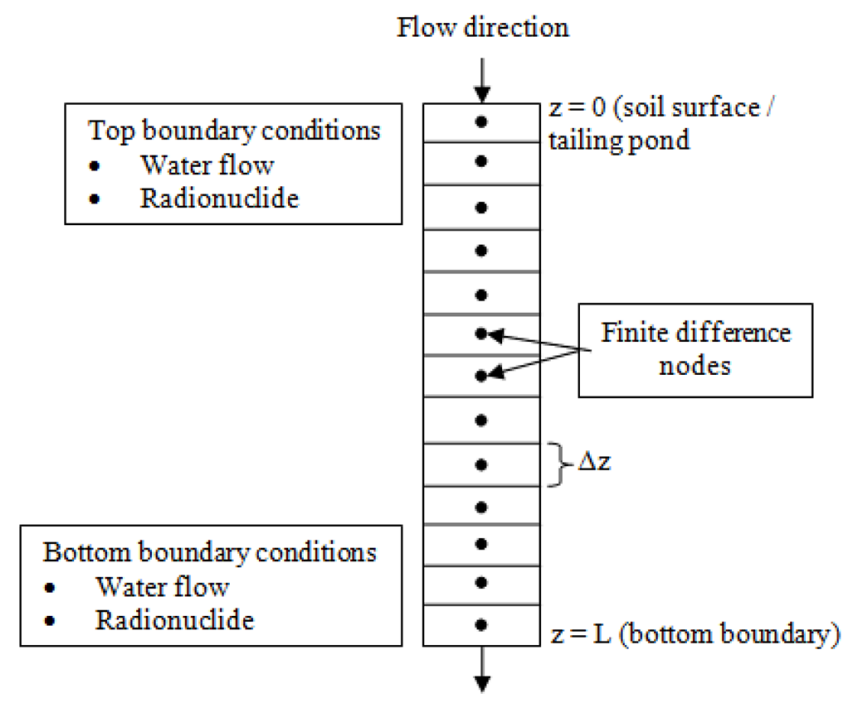

Fig. 3. Graphical representation of boundary conditions for one-dimensional domain.

to be free from contamination, and subsequently the initial values of all radionuclides concentration are assumed to be zero. The concentration of ${ }^{238} \mathrm{U}$ and ${ }^{234} \mathrm{U}$ in the tailing pond is $0.129 \mathrm{~Bq} / \mathrm{L}$ [2] considered as top boundary and all other radionuclides concentration in the tailing pond is assumed as zero. The concentration gradient for all radionuclide is assumed to be at zero for the bottom boundary condition. The graphical representation of boundary conditions for one-dimensional domain is shown in Fig. 3.

\subsection{Numerical Scheme}

In this present study, the transport of radionuclides from uranium tailing pond along with water flow have been described by a set of partial differential equations. The water flow equation has been solved by implicit finite difference scheme with explicit linearization of $\mathrm{K}(\mathrm{h})$ and $\mathrm{C}(\mathrm{h})$ to solve Eq. (1) described by Van Dam and Feddes [42].

$$
\begin{aligned}
& \frac{h_{n}^{j+1}-h_{n}^{j}}{\Delta t}= \\
& \frac{k_{n-(1 / 2)}^{j}\left(\frac{\left.\Delta h_{n-(1 / 2)}^{j+1}+1\right)-k_{n+(1 / 2)}^{j}\left(\frac{\left.\Delta h_{n+(1 / 2)}^{j+1}+1\right)}{\Delta z}\right.}{c_{n}^{j} \Delta z}\right.}{\Delta z}
\end{aligned}
$$

where subscript ' $n$ ' is the node number and superscript ' $j$ ' is the time level.

Further, the transport Eq. (4) and (5) were solved by implicit finite difference method. The value of cell width in the vertical direction $(\Delta z)$ is assumed to be $0.1 \mathrm{~m}$ and the time interval $(\Delta t)$ is assumed to be $500 \mathrm{~s}$ in order to meet the numerical stability.

\subsection{Verification of the Model}

A numerical model for radionuclide transport from uranium tailings pond in the unsaturated soil system has been developed.

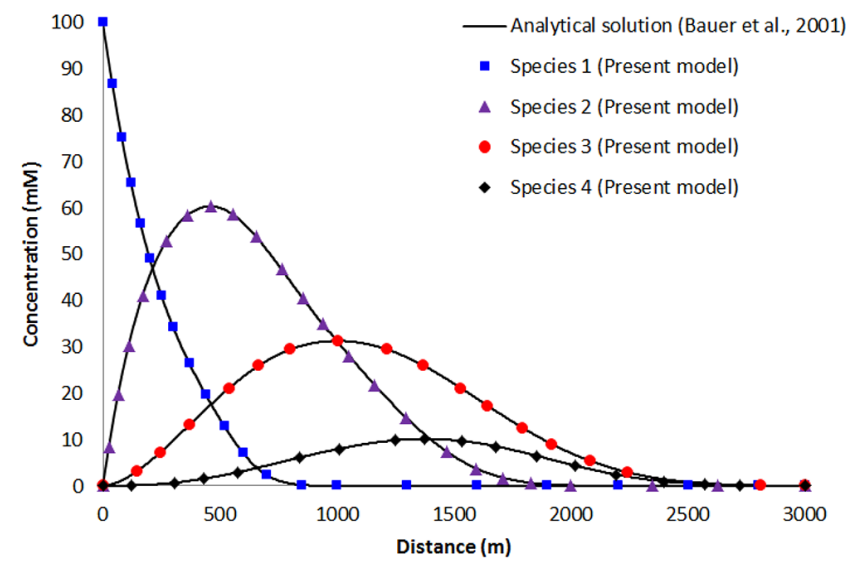

Fig. 4. Validation of one-dimensional multi-species transport with Bauer et al., (2001) at $\mathrm{T}=3,000 \mathrm{~d} ; \lambda=(7.0,5.0,4.5,3.8) \times 10^{-4}$ $\mathrm{d}^{-1} ; \mathrm{R}=(5.3,1.9,1.2,1.3) ; \mathrm{v}=1 \mathrm{~m} / \mathrm{d} ; \mathrm{C}_{0}=(100.0,0.0$, $0.0,0.0) \mathrm{mmol}$.

The developed model is verified against well-known analytical solution before applying to the uranium transport from uranium tailing pond. The developed decay chain transport model is validated by comparing the analytical solution proposed by Bauer et al. [43] by considering four species and its corresponding retardation factors. The results obtained for this verification exercise is presented in Fig. 4. The model verification results show that the present model results are found to be good matching with that of Bauer et al. [43].

\section{Results and Discussion}

The developed model is applied to a hypothetical uranium tailing pond. The soil properties used for this study are shown in Table 1. The radionuclides used in the decay chain transport model and their properties are given in Table 2. Further, the developed model is extended to various soil types and the corresponding soil hydraulic properties are presented in Table 3.

Fig. 5 provides the spatial variation of water content and the corresponding concentration profile of ${ }^{238} \mathrm{U}$ after 1,10 and $50 \mathrm{~d}$ in the unsaturated subsurface system in the presence and absence of sorption process. It is observed that the volumetric water content profile abruptly reduced from $0.207\left(\mathrm{~cm}^{3} / \mathrm{cm}^{3}\right)$ to nearly $0.1\left(\mathrm{~cm}^{3} / \mathrm{cm}^{3}\right)$ within the shallow depth (up to $50 \mathrm{~cm}$ ) in one day. However, the water content profile remains constant up to $350 \mathrm{~cm}$ and $1,450 \mathrm{~cm}$ for $10 \mathrm{~d}$ and $50 \mathrm{~d}$, respectively, i.e., the unsaturated system up to these depths continuously receives water and further reduces to the low water content $\left(0.1 \mathrm{~cm}^{3} / \mathrm{cm}^{3}\right)$. Further, it is observed from Fig. 5 that the movement of ${ }^{238} \mathrm{U}$ seems similar to the profile of water content after one day in the absence of sorption process. The concentration of ${ }^{238} \mathrm{U}$ starts at $0.129 \mathrm{~Bq} / \mathrm{L}$ from the soil surface (uranium tailing pond) and is reduced to zero at $40 \mathrm{~cm}$ depth after $1 \mathrm{~d}$. Conversely, significant delay is observed in ${ }^{238} \mathrm{U}$ concentration profile (250 cm depth after $10 \mathrm{~d}$ and $900 \mathrm{~cm}$ depth after $50 \mathrm{~d}$ ) as compared with the corresponding water content profile $(350 \mathrm{~cm}$ depth 
Table 1. Hydrodynamic Properties and Transport Parameters for an Unsaturated Zone

\begin{tabular}{lccc}
\hline \multicolumn{1}{c}{ Parameter } & Notation & Value & Reference \\
\hline Soil type & & Sand & {$[44]$} \\
Van Genuchten parameter $\left(\mathrm{m}^{-1}\right)$ & $\alpha$ & 3.35 & {$[44]$} \\
Van Genuchten parameter & $\beta$ & 2.0 & {$[44]$} \\
Van Genuchten parameter & $\eta$ & 0.5 & {$[44]$} \\
Saturated water content $\left(\mathrm{m}^{3} / \mathrm{m}^{3}\right)$ & $\theta_{\mathrm{s}}$ & 0.381 & 0.102 \\
Residual water content $\left(\mathrm{m}^{3} / \mathrm{m}^{3}\right)$ & $\theta_{\mathrm{r}}$ & 2,907 & {$[44]$} \\
Saturated hydraulic conductivity $(\mathrm{m} / \mathrm{y})$ & $\mathrm{K}_{\mathrm{s}}$ & $1.56 \times 10^{6}$ & {$[44]$} \\
Soil bulk density $\left(\mathrm{g} / \mathrm{m}^{3}\right)$ & $\rho_{\mathrm{b}}$ & 0.5 & {$[44]$} \\
Longitudinal dispersivity $(\mathrm{m})$ & $\alpha_{\mathrm{L}}$ & & {$[45]$} \\
\hline
\end{tabular}

Table 2. Uranium Decay Chain Parameters [22]

\begin{tabular}{cccc}
\hline Nuclide & Half-life, $\mathbf{T}_{\mathbf{1} / \mathbf{2}} \mathbf{( y )}$ & Decay coefficient $\boldsymbol{\lambda}_{\mathbf{i}}\left(\mathbf{y}^{-1}\right)$ & Distribution coefficient, $\boldsymbol{k}_{\boldsymbol{d i}}(\mathbf{L} / \mathbf{m g})$ \\
\hline${ }^{238} \mathrm{U}$ & $4.51 \times 10^{9}$ & $1.54 \times 10^{-10}$ & $5.00 \times 10^{-4}$ \\
${ }^{234} \mathrm{Th}$ & $6.60 \times 10^{-2}$ & $1.05 \times 10^{1}$ & $2.00 \times 10^{-3}$ \\
${ }^{234} \mathrm{U}$ & $2.48 \times 10^{5}$ & $2.79 \times 10^{-6}$ & $5.00 \times 10^{-4}$ \\
${ }^{230} \mathrm{Th}$ & $8.00 \times 10^{4}$ & $8.66 \times 10^{-6}$ & $2.00 \times 10^{-3}$ \\
${ }^{226} \mathrm{Ra}$ & $1.60 \times 10^{3}$ & $4.33 \times 10^{-4}$ & $5.00 \times 10^{-4}$ \\
${ }^{222} \mathrm{Rn}$ & $1.05 \times 10^{-2}$ & $6.6 \times 10^{1}$ & 0.00 \\
${ }^{210} \mathrm{~Pb}$ & $2.20 \times 10^{1}$ & $3.15 \times 10^{-2}$ & $3.00 \times 10^{-4}$ \\
${ }^{210} \mathrm{Bi}$ & $1.37 \times 10^{6}$ & $5.06 \times 10^{-7}$ & $3.00 \times 10^{-4}$ \\
${ }^{210} \mathrm{Po}$ & $3.79 \times 10^{-1}$ & $1.83 \times 10^{0}$ & $1.50 \times 10^{-4}$ \\
\hline
\end{tabular}

Table 3. Hydraulic Properties and Van Genuchten Fitting Parameters for Various Types of Soil [46]

\begin{tabular}{cccccccc}
\hline Soil type & \% of sand & \% of clay & $\boldsymbol{\alpha}$ & $\boldsymbol{\beta}$ & $\boldsymbol{\theta}_{\boldsymbol{r}}$ & $\boldsymbol{\theta}_{\boldsymbol{s}}$ & $\boldsymbol{K}_{\boldsymbol{s}}$ \\
\hline Sand & 92.7 & 2.9 & 14.5 & 2.68 & 0.045 & 0.43 & 2,602 \\
Silt & 5.8 & 9.5 & 1.6 & 1.37 & 0.034 & 0.46 & 22 \\
\hline
\end{tabular}

after $10 \mathrm{~d}$ and 1,450 $\mathrm{cm}$ depth after $50 \mathrm{~d}$ ). Additionally, the results of simulation indicate that there is strong delay in movement of ${ }^{238} \mathrm{U}$ in the presence of sorption. This is because of the distribution capacity of ${ }^{238} \mathrm{U}$ on soil particles $\left(5.00 \times 10^{-4}\right.$ $\mathrm{L} / \mathrm{mg}$ ) which hold huge amount of ${ }^{238} \mathrm{U}$ concentration as solid phase, which retard the movement ${ }^{238} \mathrm{U}$ in the aqueous phase. Due to the sorption process the concentration of ${ }^{238} \mathrm{U}$ becomes zero form $0.129 \mathrm{~Bq} / \mathrm{L}$ from its source at 1.5, 2.5 and $5 \mathrm{~cm}$ depth after 1, 10 and $50 \mathrm{~d}$, respectively. A closer observation between the presence and absence of sorption process implies that there is approximately $99 \%$ reduction in depth of penetration on ${ }^{238} \mathrm{U}$ concentration with the sorption process. It can be concluded from Fig. 5 that the water content variation in the unsaturated soil is directly affecting the movement of ${ }^{238} \mathrm{U}$ concentration. The presence of sorption leads to retard the movement of ${ }^{238} \mathrm{U}$ concentration, which actually aids to minimize the ${ }^{238} \mathrm{U}$ concentration in the deeper zone.

Fig. 6 shows the evolution of the water content for different infiltration velocity and its associated ${ }^{238} \mathrm{U}$ transport in unsaturated soil in the presence and absence of sorption process for $10 \mathrm{~d}$. The water content starts at $0.17 \mathrm{~m}^{3} / \mathrm{m}^{3}$ from the soil surface and gradually reduced to $0.1 \mathrm{~m}^{3} / \mathrm{m}^{3}$ at the depth of approximately $100 \mathrm{~cm}$ for the infiltration rate of $1 \mathrm{~m} / \mathrm{y}$ with the saturated hydraulic conductivity of 2,907 m/y. Moreover, it can be observed from Fig. 6 that the water contents at the soil surface are 0.17 , 0.207 and $0.22 \mathrm{~m}^{3} / \mathrm{m}^{3}$ when the infiltration rates are 1,10 and $20 \mathrm{~m} / \mathrm{y}$, respectively. The higher infiltration rate eventually attempts the water content to move deeper in the unsaturated porous media. For example, as the infiltration velocity increases $(10 \mathrm{~m} / \mathrm{y}$ and $20 \mathrm{~m} / \mathrm{y})$, a relatively large amount of water content is retained in the soil surface $\left(0.207 \mathrm{~m}^{3} / \mathrm{m}^{3}\right)$, and subsequently the depth of movement of water content is also increased (maximum water content is observed up to the depth of 250 $\mathrm{cm}$ and $500 \mathrm{~cm}$ for the infiltration rate of $10 \mathrm{~m} / \mathrm{y}$ and $20 \mathrm{~m} / \mathrm{y}$, respectively). Further, the results show that the concentration of ${ }^{238} \mathrm{U}$ is reduced from $0.129 \mathrm{~Bq} / \mathrm{L}$ at the soil surface to zero at the depth of $75 \mathrm{~cm}, 250 \mathrm{~cm}$ and $400 \mathrm{~cm}$ for the infiltration rate of 1,10 and $20 \mathrm{~m} / \mathrm{y}$ in the absence of sorption process. This shows the typical water content variation in the unsaturated soil is influencing the transport of ${ }^{238} \mathrm{U}$ and the variation in 

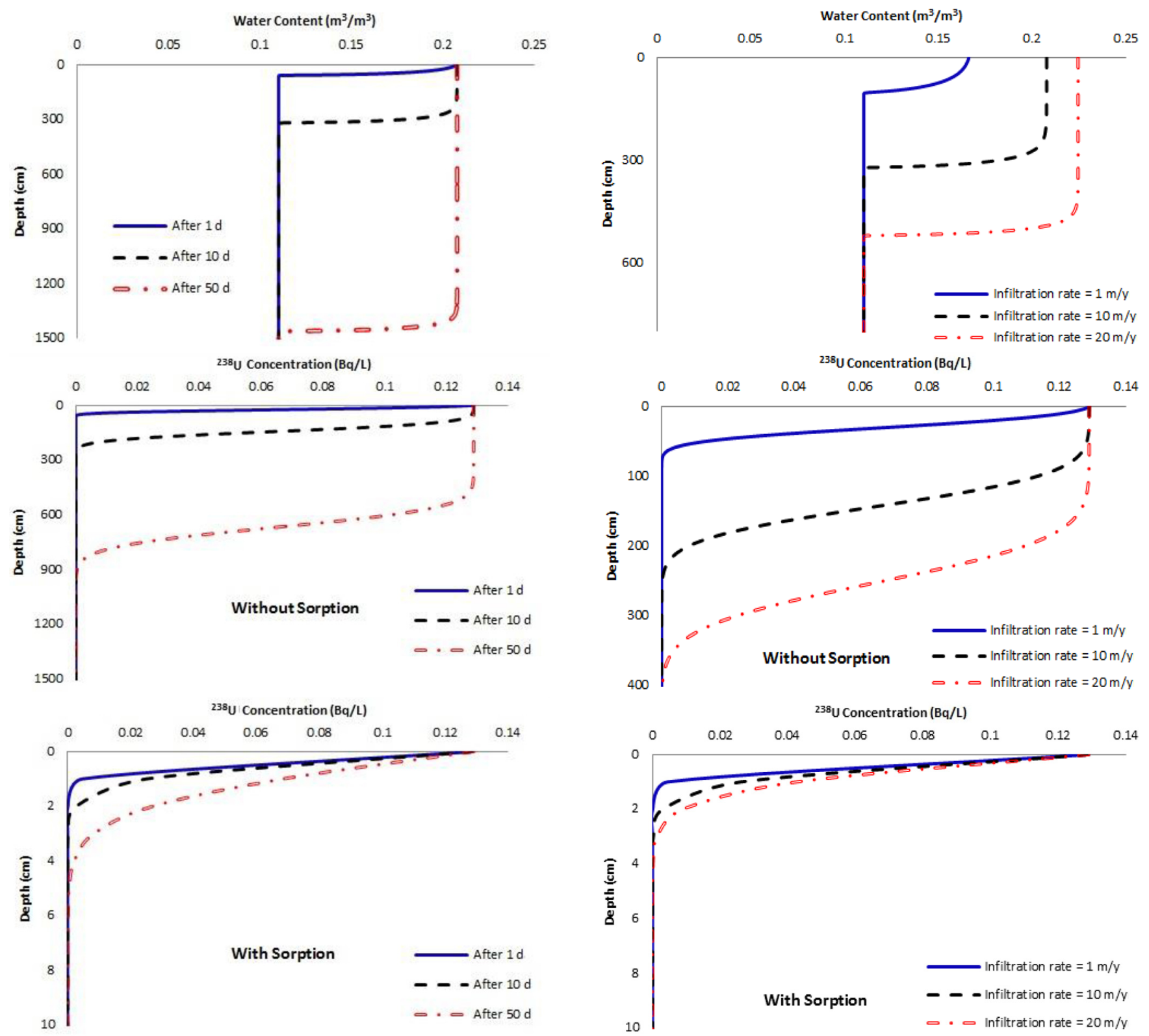

Fig. 5. Effect of water content on ${ }^{238} U$ concentration in unsaturated porous media in the presence and absence of sorption process.

infiltration is also impacting the depth of penetration. The similar trent is also observed for ${ }^{238} \mathrm{U}$ transport in the presence of sorption process with considerable delay. This delay can be explained by the retradation induced by the solid phase of ${ }^{238} \mathrm{U}$ during the sorption phenomina. It can be concluded from Fig. 6 that, the behavior of variation in the water content distributions during various infiltration rates is significantly affecting the movement of ${ }^{238} \mathrm{U}$ in the unsaturated sub-surface system.

Fig. 7 provides the spatial distribution of ${ }^{238} \mathrm{U}$ and its progenies in the absence of sorption process in the unsaturated sandy soil with the assumed infiltration rate of $10 \mathrm{~m} / \mathrm{y}$ during 1,5 and $10 \mathrm{y}$. It is observed from Fig. 7 that there is a maximum

Fig. 6. Effect of infiltration rate on the transport of ${ }^{238} \mathrm{U}$ in unsaturated porous media for the period of $10 \mathrm{~d}$.

concentration $(0.129 \mathrm{~Bq} / \mathrm{L})$ observed for ${ }^{238} \mathrm{U}$ and ${ }^{234} \mathrm{U}$ at the soil surface (uranium tailing pond) and it is further reduced to zero concentration as the depth increases. Conversely, all other progenies initially start from very low concentration (nearly $0 \mathrm{~Bq} / \mathrm{L}$ ) at the soil surface and gradually increase to their corresponding peak concentration with depth and finally become zero concentration followed by its asymptoticity. The order of peak concentrations is observed such as ${ }^{238} \mathrm{U}={ }^{234} \mathrm{U}>{ }^{230} \mathrm{Th}$ $>{ }^{226} \mathrm{Ra}>{ }^{234} \mathrm{Th}>{ }^{210} \mathrm{~Pb}>{ }^{210} \mathrm{Bi}>{ }^{222} \mathrm{Rn}>{ }^{210} \mathrm{Po}$. As soon as the concentration of ${ }^{238} \mathrm{U}$ is available, the decay starts, gets converted into ${ }^{234} \mathrm{Th}$, and subsequently into ${ }^{234} \mathrm{U}$ concentration. As ${ }^{234} \mathrm{U}$ is abundantly available from the source at the soil surface; 

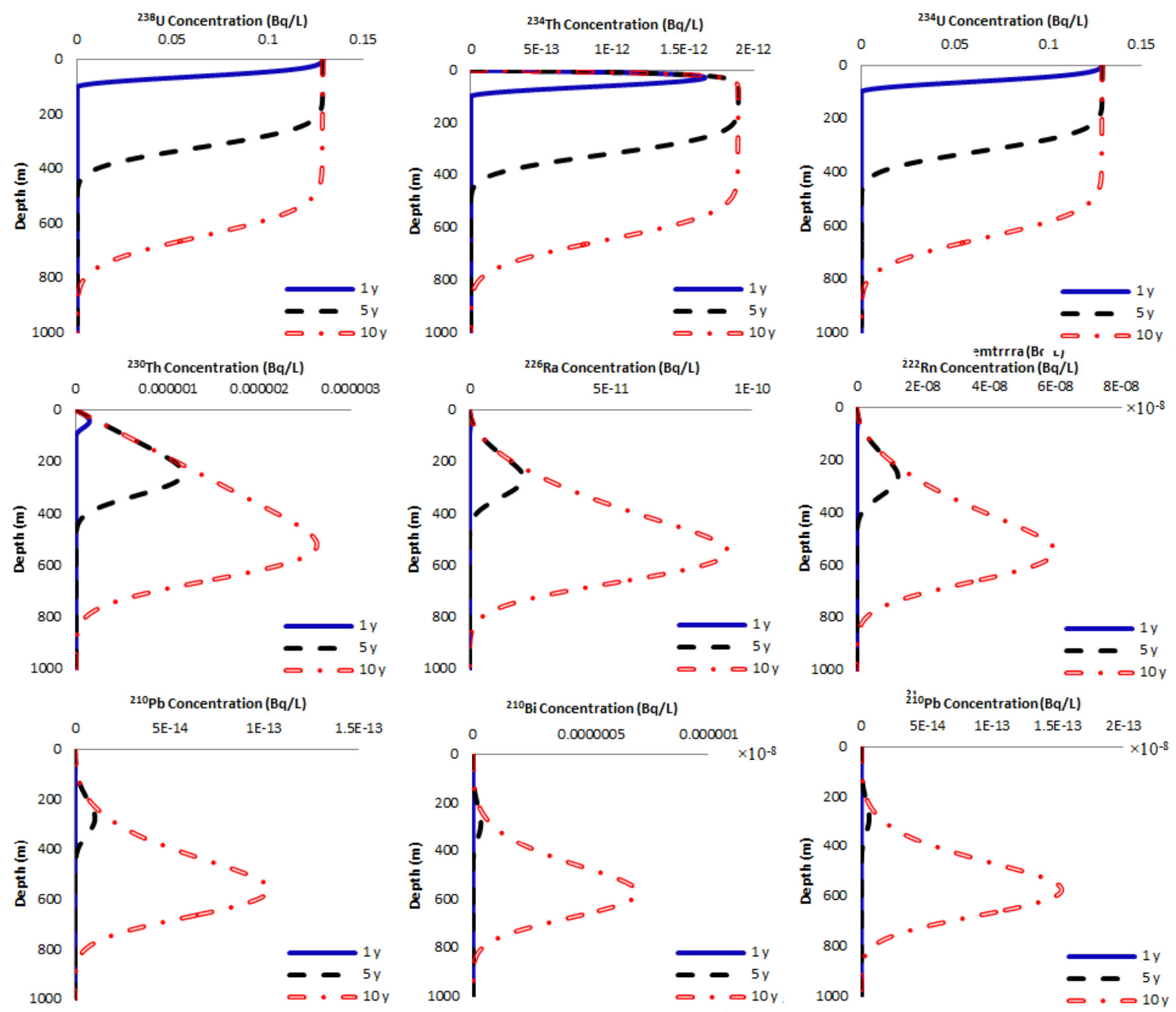

Without sorption process in sandy soil

Fig. 7. Concentration profile for ${ }^{238} \mathrm{U}$ and its progenies during various intervals without considering sorption process in unsaturated sandy soil.

its concentration profile is similar to ${ }^{238} \mathrm{U}$. Further, the decay of ${ }^{234} \mathrm{U}$ produces the remaining progenies in the decay chain reaction. The lowest ${ }^{210} \mathrm{Po}$ concentration is due to the last product in the decay chain and relatively its own high decay rate (1.83 $\left.\mathrm{y}^{-1}\right)$. It is keenly observed from Fig. 7 that, the second lowest peak concentration of ${ }^{222} \mathrm{Rn}$ due to the highest decay rate (6.6 $\times 10^{1} \mathrm{y}^{-1}$ ) among all the uranium progenies in the uranium decay chain reaction. All the results present in Fig. 5 are independent of sorption process and the variations in the concentrations are observed only based on the respective decay rate. It is further observed that all the ${ }^{238} \mathrm{U}$ and its progenies are available up to the depth of $800 \mathrm{~m}$ after $10 \mathrm{y}$ and dangerous for the deeper zone in the unsaturated sandy soil. Thus it can be concluded from Fig. 7 that the concentration of ${ }^{238} \mathrm{U}$ and
${ }^{234} \mathrm{U}$ are continuously arrived the deeper depth from the soil surface (uranium tailing pond) for longer time interval and an enhanced peak concentrations are observed at a various depths (50, 250 and $550 \mathrm{~m}$ ) at various time interval (1, 5 and $10 \mathrm{y}$ ) for all other ${ }^{238} \mathrm{U}$ progenies except ${ }^{234} \mathrm{Th}$ concentration.

The spatial distribution of ${ }^{238} \mathrm{U}$ and its progenies during various intervals in the presence of sorption process in unsaturated sandy soil has been illustrated in Fig. 8. Since the sorption process of all the ${ }^{238} \mathrm{U}$ and its progenies is considered in this simulation, a significant delay in movement and the reduction in peak are observed in all ${ }^{238} \mathrm{U}$ and its progenies concentration. It is observed that there are approximately one to two order of magnitude reductions in peaks for all species except ${ }^{238} \mathrm{U}$ and ${ }^{234} \mathrm{U}$ from Fig. 7 and 8 at $10 \mathrm{y}$. This peak reduction is due to the consideration 

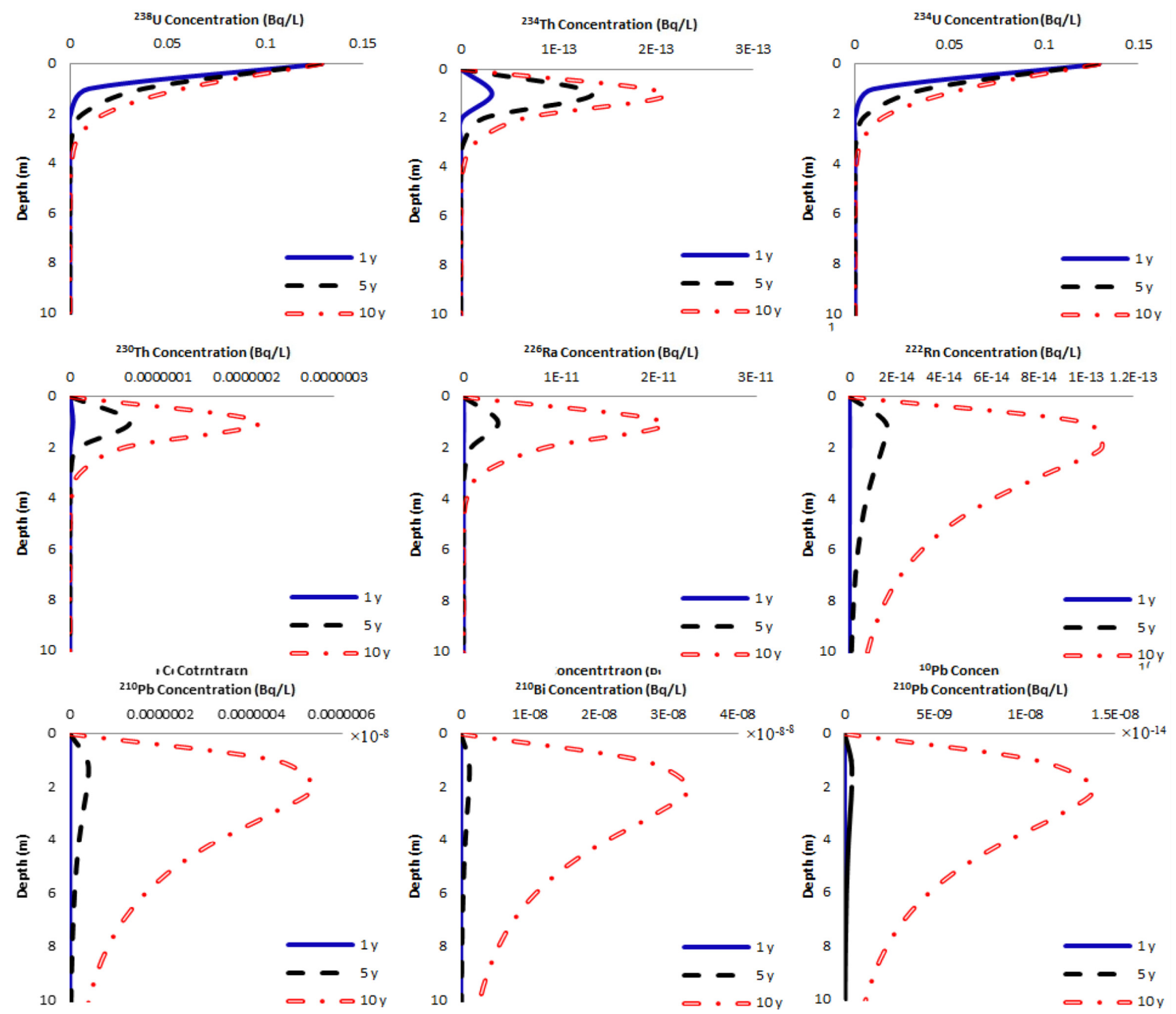

With sorption process in sandy soil

Fig. 8. Concentration profile for ${ }^{238} \mathrm{U}$ and its progenies during various intervals in the presence of sorption process in unsaturated sandy soil.

of sorption process. Moreover, the maximum concentration of ${ }^{238} \mathrm{U}$ and ${ }^{234} \mathrm{U}$ in the soil surface is also abruptly reduced when depth increases, but which is moving long depth in the case of absence of sorption process. It is further observed that the peak concentration of ${ }^{222} \mathrm{Rn}$ is also reduced to one order even though the distribution coefficient is zero as compared to all other species. This reduction happens due to the distribution coefficients of the previous species which reduce its corresponding concentration in the aqueous phase of the decay chain and in turn, lead to the considerable reduction in peak ${ }^{222} \mathrm{Rn}$ concentration. Essentially, the sorption process hinders the movement of all the species in the aqueous phase due to its corresponding distribution coefficient which helps to attract the species from the aqueous phase to the solid phase. The order of peak concentrations in the sorption process is similar as the absence of sorption process such as ${ }^{238} \mathrm{U}={ }^{234} \mathrm{U}>{ }^{230} \mathrm{Th}>{ }^{226} \mathrm{Ra}>{ }^{234} \mathrm{Th}>{ }^{210} \mathrm{~Pb}>{ }^{210} \mathrm{Bi}$ $>{ }^{222} \mathrm{Rn}>{ }^{210} \mathrm{Po}$ except the order of reduction in peak concentration for ${ }^{238} \mathrm{U}$ and its progenies. Further, it is observed from Fig. 8 that the concentration is virtually negligible after $1 \mathrm{y}$ and $5 \mathrm{y}$ as compared with $10 \mathrm{y}$. Moreover, the depth of penetration of ${ }^{238} \mathrm{U}$ and its progenies is reduced to less than $10 \mathrm{~m}$ and the peak is observed at nearly $2 \mathrm{~m}$ depth due to the presence of sorption process, whereas the ${ }^{238} \mathrm{U}$ and its progenies move up to $800 \mathrm{~m}$ and the peak is observed at nearly $550 \mathrm{~m}$ depth when the sorption process is not considered after $10 \mathrm{y}$. Since, the half-lives of the parent radionuclides are very long [22], it is great possibility that the concentration of ${ }^{238} \mathrm{U}$ and its progenies can move in deeper depth even though the sorption process is considered. 

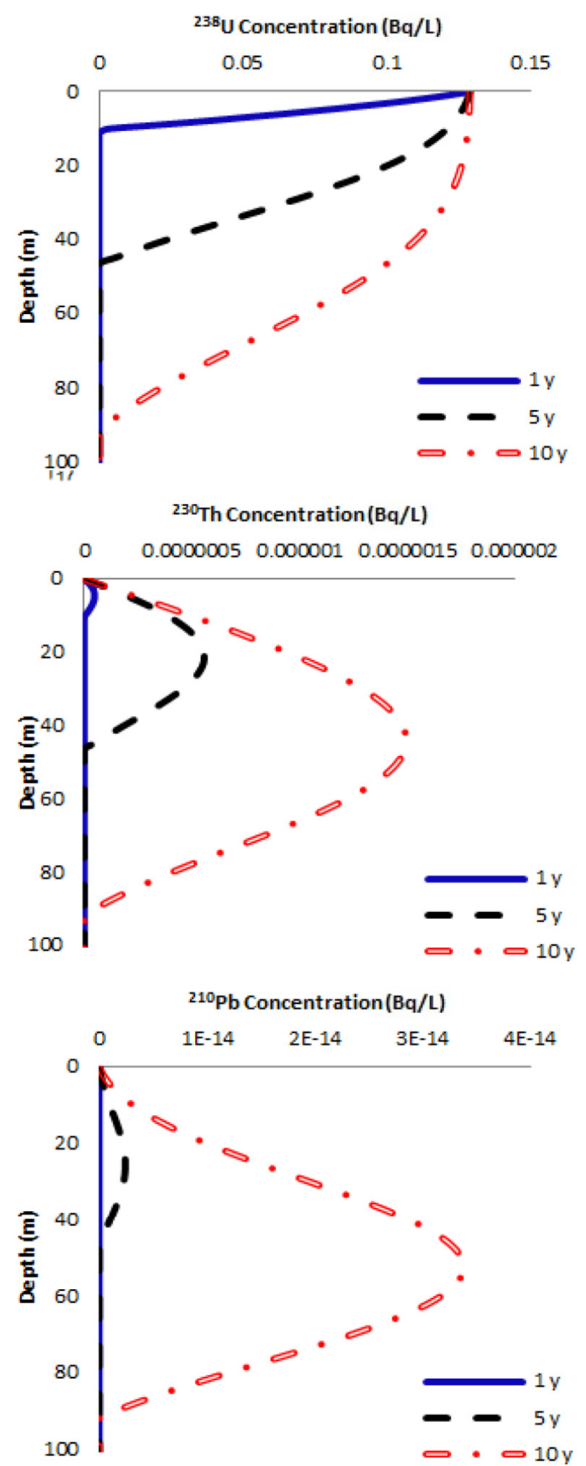
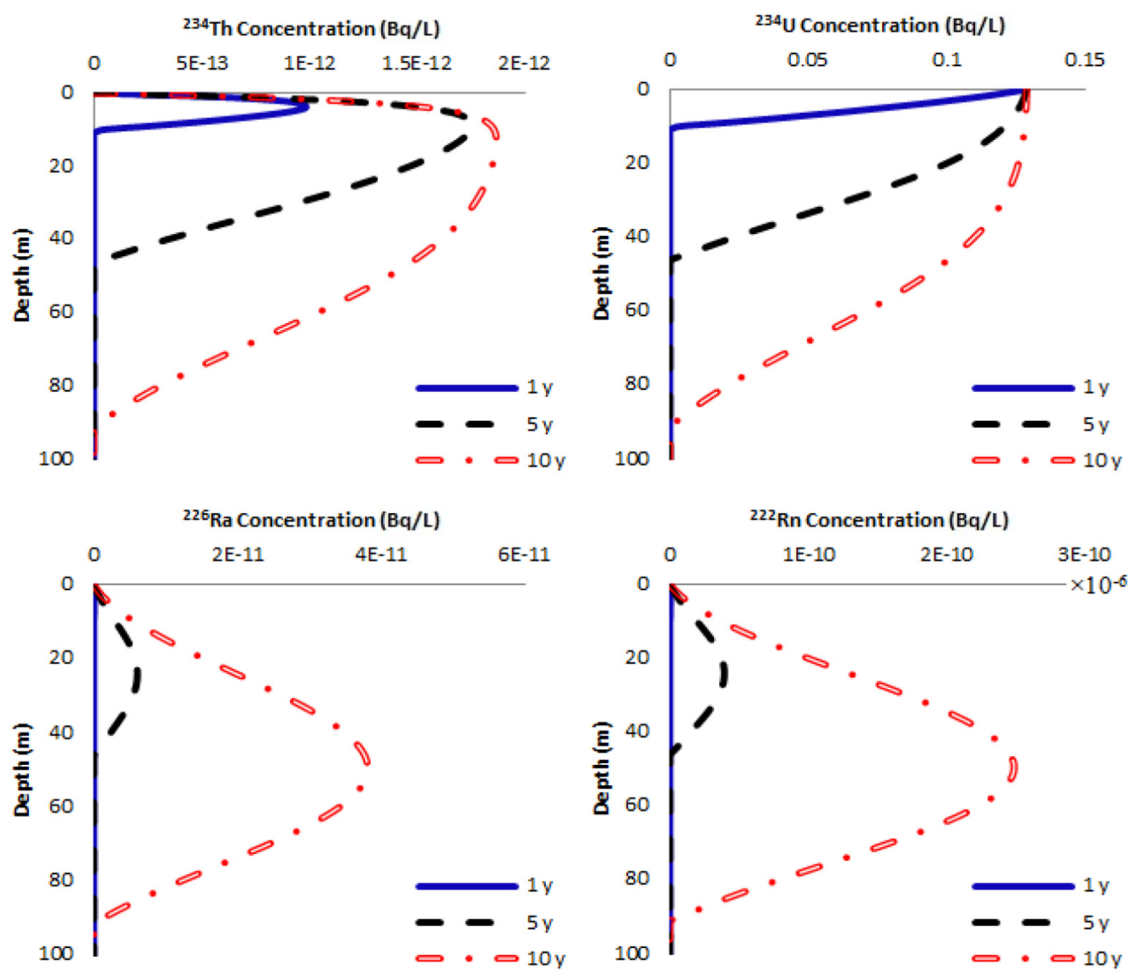

${ }^{210} \mathrm{Bi}$ Concentration $(\mathrm{Bq} / \mathrm{L})$
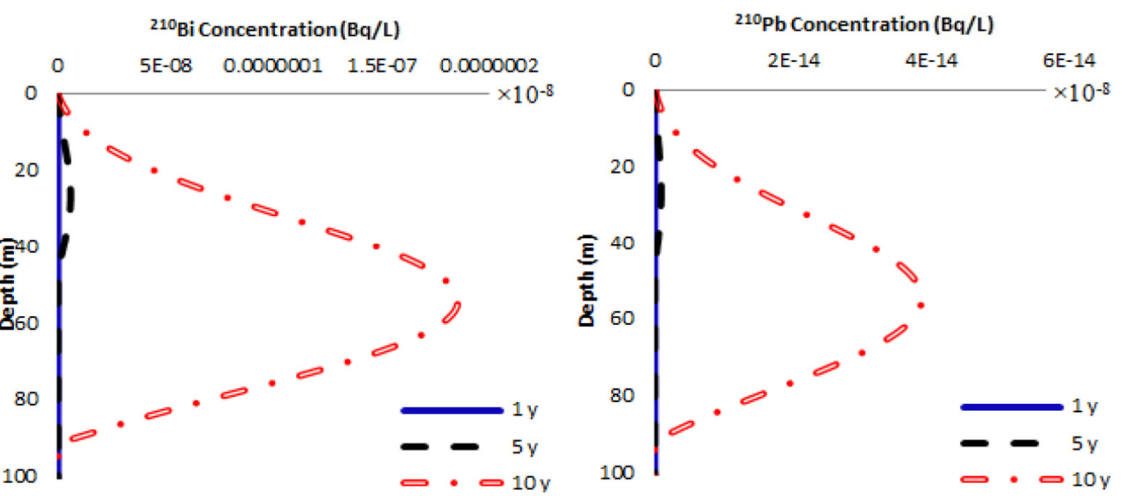

Without sorption process in silty soil

Fig. 9. Concentration profile for ${ }^{238} \mathrm{U}$ and its progenies during various intervals without considering sorption process in unsaturated silty soil.

Fig. 9 provides the spatial distribution of ${ }^{238} \mathrm{U}$ and its progenies in the absence of sorption process in the unsaturated silty soil with the assumed infiltration rate of $3 \mathrm{~m} / \mathrm{y}$ during 1,5 and $10 \mathrm{y}$. The water content is varied from $0.438 \mathrm{~m}^{3} / \mathrm{m}^{3}$ at the soil surface and gradually reduced to $0.099 \mathrm{~m}^{3} / \mathrm{m}^{3}$ at the depth of approximately $12 \mathrm{~m}, 50 \mathrm{~m}$ and $100 \mathrm{~m}$ (not shown in the Fig. 9) for the infiltration rate of $3 \mathrm{~m} / \mathrm{y}$ with the saturated hydraulic conductivity of $22 \mathrm{~m} / \mathrm{y}$ after 1, 5 and $10 \mathrm{y}$, respectively. It can be noted that the concentration of ${ }^{238} \mathrm{U}$ and ${ }^{234} \mathrm{U}$ is following similar trend with maximum inflow concentration of $0.129 \mathrm{~Bq} / \mathrm{L}$ at the soil surface and reducing to zero at 10, 45 and $90 \mathrm{~m}$ depth after 1, 5 and $10 \mathrm{y}$, respectively. As compared with the sandy soil (Fig. 7) the concentration movement with respect to the depth is significantly reduced in the silty soil, i.e., the concentration of ${ }^{238} \mathrm{U}$ and its progenies are become zero at the depth of 100, 450 and $800 \mathrm{~m}$ in the sandy soil whereas it is reduced to 10, 45 and $90 \mathrm{~m}$ in the silty soil (approximately $90 \%$ reduction in movement). Similarly, the peak concentrations are also observed in the shallow depths in the silty soil as compared with sandy soil (For example, the peak concentration of ${ }^{230} \mathrm{Th}$ is $50 \mathrm{~m}$ in the silty soil and $550 \mathrm{~m}$ in the sandy soil for $10 \mathrm{y}$ ). This reduction in movement in silty soil is primarily due to the decrease of two orders in hydraulic conductivity and other changes in soil hydraulic parameters such as water content, pressure head and van Genuchten parameters (Table 3) as compared with the sandy soil. However, the order of peak concentrations is relatively similar which is observed in the sandy soil such as ${ }^{238} \mathrm{U}={ }^{234} \mathrm{U}>{ }^{230} \mathrm{Th}>{ }^{226} \mathrm{Ra}>{ }^{234} \mathrm{Th}>{ }^{210} \mathrm{~Pb}>$ 

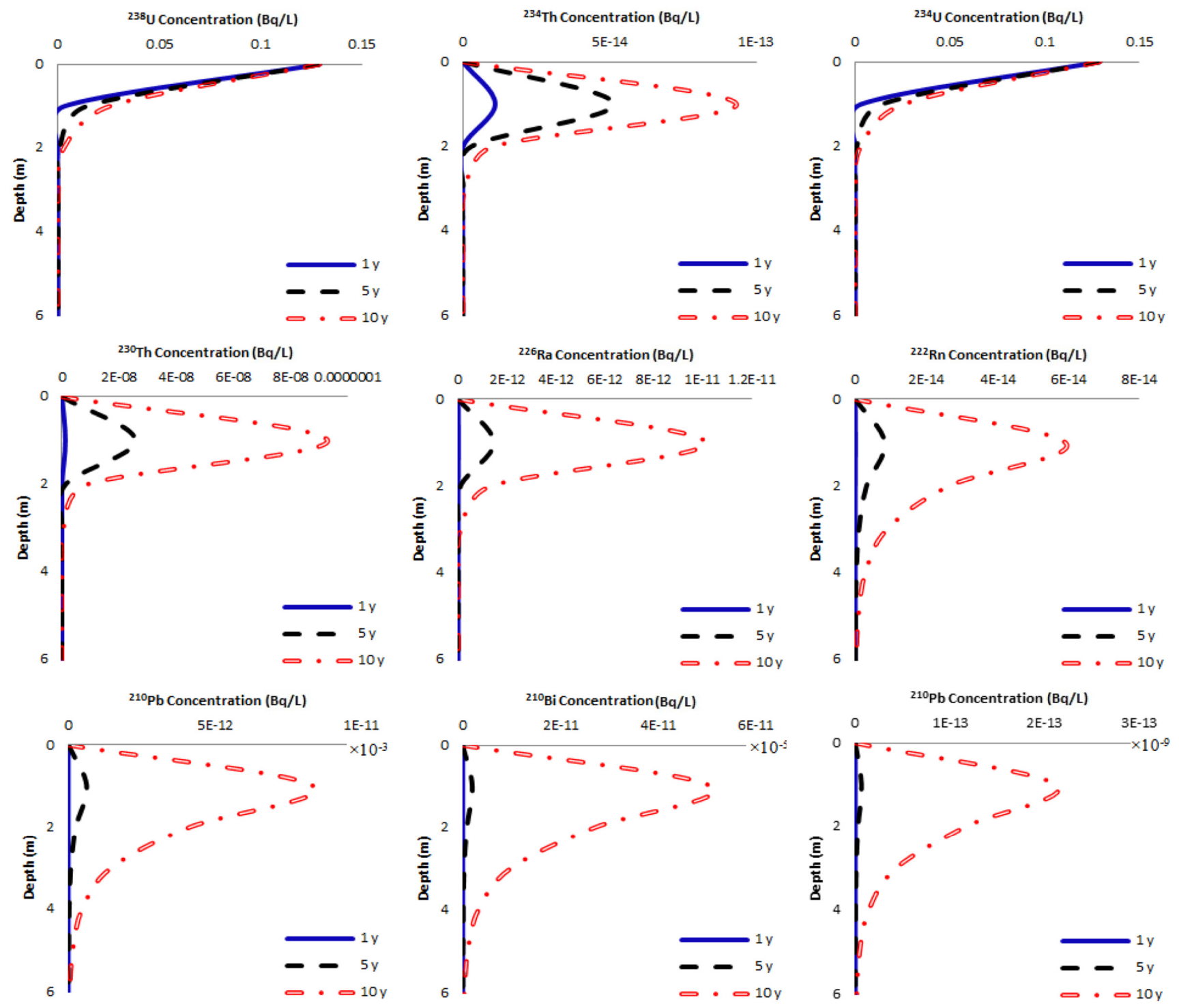

With sorption process in silty soil

Fig. 10. Concentration profile for ${ }^{238} \mathrm{U}$ and its progenies during various intervals in the presence of sorption process in unsaturated silty soil.

${ }^{210} \mathrm{Bi}>{ }^{222} \mathrm{Rn}>{ }^{210} \mathrm{Po}$. Further, it is keenly observed that the maximum concentration of ${ }^{238} \mathrm{U}$ and ${ }^{234} \mathrm{U}$ are reducing with respect to depth in the silty soil, while the same (maximum) concentrations are observed for larger depths in sandy the soil (Fig. 7). For instance, the concentration of ${ }^{238} U$ and ${ }^{234} U$ are constant up to the depth of 250 and $550 \mathrm{~m}$ and slowly becoming zero in the sandy soil (Fig. 7), whereas the maximum concentration starts declining immediately just below the soil surface (uranium tailing pond as source) in the silty soil (Fig. 9) due to its corresponding soil hydraulic properties. Thus, it can be concluded from Fig. 9 that the ${ }^{238} \mathrm{U}$ and its progenies in the absence of sorption process in the unsaturated silty soil is significantly reduced its depth of movement predominantly due to the reduced unsaturated hydraulic conductivity and other soil hydraulic pa- rameters such as water content, pressure head and van Genuchten parameters, which in turn, the enhance availability of ${ }^{238} \mathrm{U}$ and its progenies are in the shallow depths. However, the concentration of ${ }^{238} \mathrm{U}$ and its progenies are speared up to $90 \mathrm{~m}$ depth after $10 \mathrm{y}$, which shows that the groundwater aquifers may get affected if the water table is shallow.

Fig. 10 describes the spatial distribution of ${ }^{238} \mathrm{U}$ and its progenies in the presence of sorption process in the unsaturated silty soil. The ${ }^{238} \mathrm{U}$ and ${ }^{234} \mathrm{U}$ concentrations are released from the uranium tailing pond at the soil surface which have higher concentration $(0.129 \mathrm{~Bq} / \mathrm{L})$ and become zero at $1 \mathrm{~m}$ after $1 \mathrm{y}$ but very marginal downward movement is observed after 5 and 10 years. Similarly, other progenies of ${ }^{238} \mathrm{U}$ are also shown a low depth of transport in the unsaturated silty soil. This significant 
retardation in movement on ${ }^{238} \mathrm{U}$ and its progenies is predominantly happened by the sorption process of all the uranium species and the low hydraulic conductivity of soil. Approximately 90\% reduction in the depth of penetration is observed in the sorption process when compared Fig. 10 with 9; (zero concentration is observed nearly at 1, 3 and $5 \mathrm{~m}$ in the presence of sorption process and 10, 45 and $90 \mathrm{~m}$ in the absence of sorption process after 1, 5 and $10 \mathrm{y}$ ); on the other hand almost 99\% reduction in depth of penetration is observed in silty soil (Fig. 10) as compared with the sandy soil (Fig. 8) in the presence of sorption process (i.e., zero concentration is observed nearly at 1,3 and $5 \mathrm{~m}$ in the silty soil and 100,450 and $800 \mathrm{~m}$ in the in sandy soil with the sorption process after 1, 5 and $10 \mathrm{y}$ ). Moreover, it is observed from Fig. 9 and 10 that the peak concentration of all the uranium species except ${ }^{238} \mathrm{U}$ and ${ }^{234} \mathrm{U}$ are reduced nearly one order in the presence of sorption process as compared with the absence of sorption phenomena. It can be concluded from Fig. 10 that the concentration of ${ }^{238} \mathrm{U}$ and its progenies vanish at very shallow depths (approximately before $10 \mathrm{~m}$ ) and offer a positive impact to stop the groundwater contamination.

\section{Conclusions}

In the present study, a numerical model is developed to describe the transport of ${ }^{238} \mathrm{U}$ and its progenies in the vadose zone from uranium tiling pond situated on the soil surface. The one-dimensional coupled water flow and ${ }^{238} \mathrm{U}$ and its progenies decay chain reaction is developed using implicit finite difference scheme. In addition, this study is also extended to perform the movement of ${ }^{238} \mathrm{U}$ and its progenies concentration in different soils such as sand and silt. From the developed model, the following conclusions are arrived:

i ) The vertical downward transport of ${ }^{238} \mathrm{U}$ and its progenies from uranium tailing pond at soil surface is highly dependent on the water content variation in the unsaturated soil and its other soil hydraulic properties such as unsaturated hydraulic conductivity, pressure head and van Genuchten parameters.

ii) The downward movement of ${ }^{238} \mathrm{U}$ and its progenies from the uranium tailing pond results in higher concentrations at the shallow depth irrespective of sorption process in the silty soil, whereas considerable increase in concentrations is observed at the deeper depth in the sandy soil. This is due to the high hydraulic conductivity accompanied by the increase in other soil hydraulic properties which yield a larger depth of movement in the sandy soil as compared with the silty soil.

iii) While, silt transmit a relatively lesser uranium concentration down the ground surface, the sand or alluvium transport a relatively larger fraction of uranium vertically downwards and hence, it is more likely that this particular geological unit has more probability of potentially contaminating the saturated groundwater system. On the contrary, with reference to root zone uptake, it is the silty formations that retain the uranium in a relatively larger amount and subsequently contaminate the root zone in the unsaturated zone. Further, sorption plays a vital role in deciding the resultant retardation, and in turn, the total migration pathway. Thus, a coupled effect of sorption and a given geological unit decide the resultant uranium transport in a given subsurface environment.

In over all, the presence of sorption process in the silty soil significantly helps to avert the groundwater contamination, especially at deeper depths and for larger span. Future studies can be intended to integrate other mechanisms such as evaporation, root uptake, surface runoff, degradation in uranium pond and other climatic conditions to achieve the combined effect of all the coupled processes on the equivalent system to develop a comprehensive model.

\section{References}

1. Robinson P. Uranium mill tailings remediation performed by the US DOE: An overview. US DOE; 2004.

2. Elango L, Brindha K, Kalpana L, Sunny F, Nair RN, Murugan R. Groundwater flow and radionuclide decay-chain transport modeling around a proposed uranium tailings pond in India. Hydrogeol. J. 2012;20:797-812.

3. Haile SS. VS2DRT: Variably saturated two dimensional reactive transport modelling in the vadose zone. Freiberg, Germany: TU Bergakademie Freiberg; 2013.

4. IAEA. The long term stabilization of uranium mill tailings. International Atomic Energy Agency, Austria; 2004.

5. Bossew P, Kirchner G. Modelling the vertical distribution of radionuclides in soil. Part 1: The convection-dispersion equation revisited. J. Environ. Radioact. 2004;73:127-150.

6. Saleh TA. Mercury sorption by silica/carbon nanotubes and silica/activated carbon: A comparison study. J. Water Supply Res. Technol. AQUP 2015:64:892-903.

7. Gupta VK, Ali I, Saleh TA, Nayak A, Agarwal S. Chemical treatment technologies for waste-water recycling - An overview. RSC Adv. 2012:2:6380-6388.

8. Saleh TA, Agarwal S, Gupta VK. Synthesis of MWCNT/MnO and their application for simultaneous oxidation of arsenite and sorption of arsenate. Appl. Catal. B-Environ. 2011:106:46-53.

9. Saleh TA. Nanocomposite of carbon nanotubes/silica nanoparticles and their use for adsorption of $\mathrm{Pb}(\mathrm{II})$ : From surface properties to sorption mechanism. Desalin. Water Treat. 2016:57:10730-10744.

10. Gupta VK, Ali I, Saleh TA, Siddiqui MN, Agarwal S. Chromium removal from water by activated carbon developed from waste rubber tires. Environ. Sci. Pollut. Res. 2013:20:1261-1268.

11. Saleh TA. Isotherm, kinetic, and thermodynamic studies on $\mathrm{Hg}(\mathrm{II})$ adsorption from aqueous solution by silica- multiwall carbon nanotubes. Environ. Sci. Pollut. Res. 2015:22:16721-16731.

12. Zare F, Ghaedi M, Daneshfar A, et al. Efficient removal of radioactive uranium from solvent phase using AgOH-MWCNTs nanoparticles: Kinetic and thermodynamic study. Chem. Eng. J. 2015:273:296-306. 
13. Saleh TA, Naeemullah, Tuzen M, Sarı A. Polyethylenimine modified activated carbon as novel magnetic adsorbent for the removal of uranium from aqueous solution. Chem. Eng. Res. Design 2017:117:218-227.

14. Camus H, Little R, Acton D, et al. Long-term contaminant migration and impacts from uranium mill tailings. J. Environ. Radioact. 1998;42:289-304.

15. Kalf F, Dudgeon C. Analysis of long-term groundwater dispersal of contaminants from proposed Jabiluka Mine Tailings repositories. Supervising Scientist Report 143, Supervising Scientist, Canberra, Australia; 1999.

16. Zhu C, Hu FQ, Burden DS. Multi-component reactive transport modelling of natural attenuation of an acid ground-water plume at a uranium mill tailings site. J. Contamin. Hydrol. 2001;52:85-108.

17. Neves O, Matias MJ. Assessment of groundwater quality and contamination problems ascribed to an abandoned uranium mine (Cunha Baixa region, central Portugal). Environ. Geol. 2008;53:1799-1810.

18. Leijnse A, van de Weerd H, Hassanizadeh SM. Modelling uranium transport in Koongarra, Australia: The effect of a moving weathering zone. Math. Geol. 2001;33:1:1-29.

19. Tricca A, Porcelli D, Wasserburg GL. Factors controlling the groundwater transport of U, Th, Ra and Rn. J. Earth Syst. Sci. 2000;109:95-108.

20. Nitzsche O, Merkel B. Reactive transport modeling of uranium 238 and radium 226 in groundwater of the Königstein uranium mine, Germany. Hydrogeol. J. 1999;7:423-430.

21. Rotter BE, Barry DA, Gerhard JI, Small JS. Modeling U(VI) biomineralization in single- and dual-porosity porous media. Water Resour. Res. 2008;44:W08437.

22. Nair RN, Sunny F, Manikandan ST. Modelling of decay chain transport in groundwater from uranium tailings ponds. Appl. Math. Model. 2010;34:2300-2311.

23. Qian T, Li S, Ding Q, Wu G, Zhao D. Two-dimensional numerical modeling of ${ }^{90} \mathrm{Sr}$ transport in unsaturated Chinese loess under artificial sprinkling. J. Environ. Radioact. 2009:100:422-428.

24. Merk R. Numerical modeling of the radionuclide water pathway with HYDRUS and comparison with the IAEA model of SR 44. J. Environ. Radioact. 2012;105:60-69.

25. Sanchez DP, Thorne MC. Modelling the behaviour of uranium-series radionuclides in soils and plants taking into account seasonal variations in soil hydrology. J. Environ. Radioact. 2014;131:19-30.

26. Nair RN, Chopra M, Sunny F, Sharma LK, Puranik VD. Source term evaluation model for uranium tailings ponds. J. Hazard. Toxic. Radioact. Waste. 2013;17:211-217.

27. Pabich WJ, Valiela I, Hemond HE. Relationship between DOC concentration and vadose zone thickness and depth below water table in groundwater of Cape Cod, U.S.A. Biochemistry 2001;55:247-268.

28. Holden A, Fierer N. Microbial processes in the vadose zone. Vadose Zone J. 2005;4:1-21.

29. Kartha SA, Srivastava R. Effect of immobile water content on contaminant transport in unsaturated zone. $J$.
Hydro-environ. Res. 2008;1:206-215.

30. Berlin M, Suresh Kumar G, Nambi IM. Numerical modeling on fate and transport of nitrate in an unsaturated system under non-isothermal condition. Eur. J. Environ. Civil Eng. 2013;17:350-373.

31. Berlin M, Suresh Kumar G, Nambi IM. Numerical modeling of biological clogging on transport of nitrate in an unsaturated porous media. Environ. Earth Sci. 2015;73:3285-3298.

32. Wang XS, Ma MG, Li X, Zhao J, Dong P, Zhou J. Groundwater response to leakage of surface water through a thick vadose zone in the middle reaches area of Heihe River Basin, in China. Hydrol. Earth Syst. Sci. 2010;14:639-650.

33. Ye M, Pan F, Wu YS, Hu BX, Shirley C, Yu Z. Assessment of radionuclide transport uncertainty in the unsaturated zone of Yucca Mountain. Adv. Water Resour. 2007;30:118-134.

34. Kim GN, Moon JK, Lee KW. An analysis of the effect of hydraulic parameters on radionuclide migration in an unsaturated zone. Nucl. Eng. Technol. 2010;42:562-567.

35. Winograd IJ. Radioactive waste disposal in thick unsaturated zones. Sci. 1981;212:1457-1460.

36. Suchomel KH, Kreamer DK, Long A. Production and transport of carbon dioxide in a contaminated vadose zone: A stable and radioactive carbon isotope study. Environ. Sci. Technol. 1990;24:1824-1831.

37. Viswanathan HS, Robinsor BA, Gable CW, Carey JW. A geostatistical modeling study of the effect of heterogeneity on radionuclide transport in the unsaturated zone, Yucca Mountain. J. Contam. Hydrol. 2003;62-63:319-336.

38. Antonopoulos VZ. Water movement and heat transfer simulations in a soil under ryegrass. Biosyst. Eng. 2006;95:127-138.

39. Berlin M, Suresh Kumar G, Nambi IM. Numerical modeling on transport of nitrogen from wastewater and fertilizer applied on paddy fields. Ecol. Model. 2014a;278:85-99.

40. Berlin M, Suresh Kumar G, Nambi IM. Numerical modeling on the effect of dissolved oxygen on nitrogen transformation and transport in unsaturated porous system. Environ. Model. Assess. 2014b;19:283-299.

41. Van Genuchten M.Th. A closed-form equation for predicting hydraulic conductivity of unsaturated soils. Soil Sci. J. 1980;44:892-898.

42. Van Dam JC, Feddes RA. Numerical simulation of infiltration, evaporation and shallow groundwater levels with the Richards equation. J. Hydrol. 2000;233:72-85.

43. Bauer P, Attinger S, Kinzelbach W. Transport of a decay chain in homogeneous porous media: Analytical solution. J. Contam. Hydrol. 2001;49:217-239.

44. Mitchell RJ, Mayer AS. A numerical model for transient-hysteretic flow and solution transport in unsaturated porous media. J. Contam. Hydrol. 1998;50:243-264.

45. Lee MS, Lee KK, Hyun Y, Clement TP, Hamilton D. Nitrogen transformation and transport modeling in groundwater aquifers. Ecol. Model. 2006;192:143-159.

46. Carsel RF, Parrish RS. Developing joint probability distributions of soil water retention characteristics. Water Resour. Res. 1998;24:755-769. 